\title{
Desempenho agronômico da cenoura adubada com jitirana antes de sua semeadura ${ }^{1}$
}

\author{
Agronomic performance of carrot fertilized with scarlet starglory before sowing
}

\author{
Mychelle Karla Teixeira de Oliveira ${ }^{2 *}$, Francisco Bezerra Neto ${ }^{2}$, Aurélio Paes Barros Júnior ${ }^{3}$, Jailma Suerda \\ Silva de Lima² e Joserlan Nonato Moreira ${ }^{2}$
}

\begin{abstract}
Resumo - A jitirana é uma planta herbácea nativa que se apresenta como uma fonte potencial para adubação verde no nordeste semi-árido do Brasil e gera inúmeros benefícios, com destaque para o aumento da disponibilidade de nutrientes para as culturas. O objetivo do presente trabalho foi avaliar o desempenho agronômico da cenoura adubada com jitirana antes de sua semeadura. Um experimento foi conduzido na horta didática do Departamento de Ciências Vegetais da Universidade Federal Rural do Semi-Árido (UFERSA), Mossoró-RN, no período de setembro a dezembro de 2008. O delineamento experimental usado foi em blocos completos casualizados com os tratamentos arranjados em esquema fatorial 4 x $4+1$, com três repetições. O primeiro fator foi constituído pelas quantidades de jitirana incorporadas ao solo $(5,4 ; 8,8 ; 12,2$ e 15,6 t ha- em base seca) e o segundo fator pelos tempos de incorporação da jitirana ( $0 ; 10 ; 20$ e 30 dias antes da semeadura da cenoura - DAS). O tratamento adicional (testemunha) foi de $80 \mathrm{t} \mathrm{ha}^{-1}$ de esterco bovino. As características avaliadas na cenoura foram: altura das plantas, número de folhas por planta, massa seca da parte aérea, produtividade comercial, produtividade refugo e produtividade classificada. Não houve interação significativa entre os fatores quantidades de jitirana incorporadas ao solo e seus tempos de incorporação antes da semeadura da cenoura em nenhuma das características avaliadas. O melhor desempenho produtivo da cenoura foi obtido na quantidade de 15,6 $\mathrm{t} \mathrm{ha}^{-1}$ de jitirana incorporada ao solo e no tempo de 20 dias antes de sua semeadura.
\end{abstract}

Palavras-chave - Daucus carota. Merremia aegptya. Adubo verde.

\begin{abstract}
The scarlet starglory is an herbaceous plant native that is presented as a potential source for green manure in the semi-arid northeast of Brazil, and generates many benefits, especially the increased availability of nutrients for crops. The objective of this present study was to evaluate the agronomic performance of carrot fertilized with scarlet starglory before carrot sowing. An experiment was conducted at the teaching garden of the Plant Sciences Department, Universidade Federal Rural do Semi-Árido (UFERSA), Mossoró-RN, from September to December 2008. The experimental design used was a randomized complete block with treatments arranged in a $4 \times 4+1$ factorial scheme, with 3 replications. The first factor was composed of the quantities of scarlet starglory incorporated into the soil $\left(5.4 ; 8.8 ; 12.2\right.$ and $15.6 \mathrm{t} \mathrm{ha}^{-1}$ on a dry basis), and the second factor by the times of scarlet starglory incorporation into the soil $(0 ; 10 ; 20$ and 30 days before sowing of carrot - DBS). The additional treatment (control) was fertilized with $80 \mathrm{t} \mathrm{ha}^{-1}$ of cattle manure. The characteristics evaluated were: plant height, leaf number per plant, dry mass of shoot, commercial productivity, scrap productivity, classified productivity. There was no significant interaction between the quantities of scarlet starglory incorporated into the soil and its times of incorporation before carrot sowing on any of those evaluated characteristics. The highest productive performance of carrot was obtained in the amount of $15.6 \mathrm{t} \mathrm{ha}^{-1}$ of scarlet starglory incorporated into the soil at the time of 20 days prior to the carrot planting time.
\end{abstract}

Key words - Daucus carota. Merremia aegptya. Green manure.

\footnotetext{
* Autor para correspondência

${ }^{1}$ Recebido para publicação em 02/04/2010; aprovado em 28/01/2011

Parte da Dissertação de Mestrado apresentada pelo primeiro autor no Programa Pós-Graduação em Agronomia/Fitotecnia, UFERSA

2Departamento de Ciências Vegetais/UFERSA, Mossoró-RN, Brasil, 59.625-900, mkto10@hotmail.com, bezerra@ufersa.edu.br, jailmaagro@gmail.

com,moreiragronomo@hotmail.com

${ }^{3}$ Unidade Acadêmica de Serra Talhada, Universidade Federal Rural de Pernambuco_Serra Talhada-PE, Brasil, aureliojr02@yahoo.com.br
} 


\section{Introdução}

Os sistemas de produção de hortaliças no Nordeste brasileiro são feitos em sua maioria com adubação mineral e orgânica, principalmente com o uso do esterco bovino, insumo não tão barato e nem sempre de fácil aquisição.

$\mathrm{O}$ uso de fontes naturais provenientes da própria propriedade é de importância fundamental para esses sistemas de produção agrícolas, com destaque para a adoção de técnicas como a adubação verde que se destaca como uma prática de cultivo e de incorporação de restos de plantas, produzidas no local ou adicionadas, com a finalidade de preservar e/ou restaurar os teores de matéria orgânica e nutrientes do solo. Esta prática assume papel preponderante no desenvolvimento de uma produção hortícola voltada para o máximo aproveitamento e uso dos recursos disponíveis. O uso deste tipo de adubação gera inúmeros benefícios, com destaque para o aumento da disponibilidade de nutrientes para as culturas, proteção do solo contra erosão e favorecimento de organismos benéficos para a agricultura.

O uso de espécies nativas como adubo verde apresenta-se como uma alternativa adotada para suprimento de nutrientes nos solos da região semi-árida do Nordeste brasileiro. Essas espécies apresentam inúmeras vantagens diante das espécies exóticas, como menor custo de obtenção e o fato destas espécies já serem adaptadas às condições ambientais.

A jitirana é uma planta nativa da região Nordeste e muito comum durante o período chuvoso. Algumas pesquisas têm sido desenvolvidas utilizando esta planta como adubo verde na produção de hortaliças folhosas (GÓES, 2007; LIMA et al., 2008; LINHARES et al., 2009a,b,c,d,e). Segundo esses autores, a jitirana apresenta características que a classificam como promissora para uso como adubo verde, com destaque para alta produção de biomassa, concentração de nutrientes, e estreita relação $\mathrm{C} / \mathrm{N}$, o que acarreta numa rápida mineralização e liberação de nutrientes (GIACOMINI et al., 2003; OLIVEIRA et al., 2003).

A fim de fornecer maiores subsídios para o uso da jitirana como adubo verde em sistemas de cultivo com tuberosas, o presente trabalho avaliou o desempenho agroeconômico da cenoura adubada com jitirana antes de sua semeadura.

\section{Material e métodos}

O experimento foi realizado durante o período de setembro a dezembro de 2008 na horta didática do Departamento de Ciências Vegetais da Universidade
Federal Rural do Semi-Árido (UFERSA), Mossoró-RN, em solo classificado como Argissolo Vermelho Amarelo Eutrófico (EMBRAPA, 2006). O município de Mossoró situa-se a $5^{\circ} 11^{\prime}$ de latitude Sul e $37^{\circ} 20^{\prime}$ de longitude Oeste e altitude de $18 \mathrm{~m}$. Segundo Thornthwaite, o clima local é DdAa', ou seja, semiárido, megatérmico e com pequeno ou nenhum excesso d'água durante o ano, e de acordo com Köppen é BSwh', seco e muito quente, com duas estações climáticas: uma seca, que geralmente compreende o período de junho a janeiro e uma chuvosa, entre os meses de fevereiro e maio (CARMO FILHO et al., 1991).

Antes da instalação do experimento foram retiradas amostras de solo na profundidade de $0-20 \mathrm{~cm}$, as quais foram secas ao ar e peneiradas em malha de $2 \mathrm{~mm}$. Em seguida, foram analisadas no Laboratório de Química e Fertilidade de Solos da UFERSA, cujos resultados foram os seguintes: $\mathrm{pH}$ (água $1: 2,5)=7,7 ; \mathrm{Ca}=3,4 \mathrm{cmol}_{\mathrm{c}} \mathrm{dm}^{-3}$; $\mathrm{Mg}=1,00 \mathrm{cmol}_{\mathrm{c}} \mathrm{dm}^{-3} ; \mathrm{K}=0,16 \mathrm{cmol}_{\mathrm{c}} \mathrm{dm}^{-3} ; \mathrm{Na} \stackrel{\mathrm{c}}{=} 0,16$ $\mathrm{cmol}_{\mathrm{c}} \mathrm{dm}^{-3} ; \mathrm{P}=100,29 \mathrm{mg} \mathrm{dm}^{-3}$ e M.O. $=0,30 \%$.

O delineamento experimental utilizado foi em blocos completos casualizados com os tratamentos arranjados em esquema fatorial $4 \times 4+1$, com três repetições. Os tratamentos consistiram da combinação de quatro quantidades de jitirana incorporadas ao solo: 5,$4 ; 8,8 ; 12,2$ e $15,6 \mathrm{t} \mathrm{ha}^{-1}$ em base seca, com quatro tempos de incorporação da jitirana: $0 ; 10 ; 20$ e 30 dias antes da semeadura da cenoura (DAS) mais o tratamento testemunha que consistiu de cenoura adubada com $80 \mathrm{t} \mathrm{ha}^{-1}$ de esterco bovino, segundo recomendação tradicionalmente utilizada no cultivo desta hortaliça, aplicado quatro dias antes da semeadura da cenoura (IPA, 1998). Cada parcela tinha uma área total de $1,44 \mathrm{~m}^{2}$, com uma área útil de $0,80 \mathrm{~m}^{2}$. As fileiras ou linhas de plantio foram dispostas transversalmente no canteiro, espaçada entre si de $0,20 \mathrm{~m}$ e dentro da linha nos espaçamentos de $0,10 \mathrm{~m}$, resultando numa população de 500.000 plantas ha $^{-1}$.

A cultivar de cenoura (Daucus carota L.) plantada foi a Brasília, recomendada para as condições semiáridas do Nordeste brasileiro, por apresentar elevada produtividade (LOPES et al., 2008; PIMENTEL et al., 2009). Essa cultivar apresenta folhagem verde escura, raízes cilíndricas com coloração laranja-clara e baixa incidência de ombro verde ou roxo, resistência ao calor, à requeima por Alternaria e ao pendoamento prematuro.

O preparo do solo consistiu de uma gradagem, em seguida o levantamento dos canteiros realizado manualmente utilizando enxadas. Após a construção dos canteiros foi realizada uma solarização durante 30 dias com a finalidade de reduzir a população de fitopatógenos do solo, que porventura viessem a prejudicar o desenvolvimento e a produtividade da cultura da cenoura. 
A jitirana foi coletada nas proximidades do Campus da UFERSA, quando as plantas apresentavamse em plena floração, dando-se preferência aos locais onde a planta se desenvolveu sobre plantas arbóreas, sobre cercas ou onde se verificava elevada predominância da jitirana, com o objetivo de evitar a contaminação do material com outras espécies.

A jitirana coletada foi triturada em uma máquina trituradeira/picadeira, e em seguida posta para secar em uma área cimentada, até atingir umidade de $6 \%$, com intuito de que as quantidades fossem estimadas em base de matéria seca. Foram feitas análises químicas, cujos resultados para o esterco bovino e jitirana seca foram $-\mathrm{N}=1,49 \%$ e $2,14 \% ; \mathrm{P}=0,37 \%$ e $0,63 \% ; \mathrm{K}=$ $0,51 \%$ e $0,07 \%$, respectivamente.

A jitirana foi inicialmente incorporada nas parcelas referentes aos 30 dias antes da semeadura, após 10 dias foi realizada a incorporação nas parcelas de 20 dias antes do plantio, e após mais 10 dias foi incorporada nas parcelas de 10 dias antes da semeadura. Finalmente, após mais 10 dias, especificamente aos 30 dias da primeira incorporação foi realizada a incorporação no tempo zero, ou seja, no dia do plantio da cenoura. Desde a primeira incorporação foram realizadas irrigações diárias em dois turnos, com a finalidade de promover a atividade microbiana do solo no processo de decomposição.

O plantio foi realizado no dia 17/09/2008 em semeadura direta, aproximadamente $2 \mathrm{~cm}$ de profundidade, colocando-se cinco a sete sementes por cova. Aos 23 dias depois da semeadura foi realizado o desbaste, deixando-se uma planta por cova.

As irrigações foram efetuadas por um sistema de micro-aspersão, com turno de rega diário, parcelada em duas aplicações (manhã e tarde), fornecendo-se uma lâmina de água de aproximadamente $8 \mathrm{~mm} \mathrm{dia}^{-1}$. Foram realizadas ainda duas capinas manuais.

A colheita foi realizada aos 96 dias depois da semeadura (22/12/2008). Logo após a colheita, as raízes foram transportadas para o Laboratório de Pós-Colheita de Hortaliças do Departamento de Ciências Vegetais da UFERSA, para proceder às análises.

Foram avaliadas as características de desenvolvimento da parte aérea (altura de plantas, número de folhas por planta e massa seca da parte aérea), de produção comercial (produtividade comercial) e produção classificada de raízes (produtividade de raízes refugo, curtas, médias e longas). A altura média de plantas foi obtida medindo-se a partir do nível do solo até à extremidade das folhas mais altas e expressas em centímetros. O número de folhas por planta foi determinado em uma amostra de vinte plantas, contando-se o número de folhas, partindo-se das folhas basais até a última folha aberta. A massa seca da parte aérea foi determinada após secagem em estufa com circulação forçada de ar, com temperatura regulada a $65^{\circ} \mathrm{C}$, até atingir massa constante e expressa em t ha ${ }^{-1}$. A produtividade comercial e a produtividade de raízes refugo de cenoura foram obtidas a partir da massa fresca das 40 raízes da área útil da parcela, expressas em $\mathrm{t} \mathrm{ha}^{-1}$. Considerou-se como produtividade comercial as raízes livres de defeitos como, rachaduras, bifurcações, nematóides e danos mecânicos. A produtividade classificada de raízes foi obtida segundo o comprimento e maior diâmetro transversal em: longas (comprimento de 17 a $25 \mathrm{~cm}$ e diâmetro menor que $5 \mathrm{~cm}$ ), médias (comprimento de 12 a $17 \mathrm{~cm}$ e diâmetro maior que $2,5 \mathrm{~cm}$ ), curtas (comprimento de 5 a $12 \mathrm{~cm}$ e diâmetro maior que $1 \mathrm{~cm}$ ) e refugo (raízes que não se enquadram nas medidas anteriores), conforme Lana e Vieira (2000). Esta produtividade foi expressa em porcentagem. Análises de variância para as características avaliadas foram realizadas através do aplicativo software ESTAT (KRONKA; BANZATO, 1995). O procedimento de ajustamento de curva de resposta foi realizado através do software Table Curve (JANDEL SCIENTIFIC, 1991).

\section{Resultados e discussão}

Não foi observada nenhuma interação significativa entre as quantidades de jitirana e seus tempos de incorporação ao solo nas características avaliadas (FIG. de 1 a 8). No entanto, foi ajustada uma equação linear ascendente para a altura de plantas de cenoura em função das quantidades crescentes de jitirana incorporadas ao solo. Para cada incremento de uma tonelada de jitirana incorporada ao solo, observouse um aumento na altura de plantas de cenoura de aproximadamente $0,42 \mathrm{~cm}$ (FIG. 1A).

A maior altura de plantas de cenoura $(30,85 \mathrm{~cm})$ foi obtida na quantidade de jitirana incorporada ao solo de $15,6 \mathrm{t} \mathrm{ha}^{-1}$, correspondendo a um incremento de $16,1 \% \mathrm{em}$ relação à menor quantidade de jitirana incorporada. Este aumento da altura de plantas de cenoura decorrente das quantidades crescentes de jitirana incorporadas ao solo pode ser atribuído ao elevado teor de nitrogênio na jitirana incorporada $(2,14 \%)$. Além disso, a estreita relação C/N (18:1) confere a capacidade de decomposição rápida e consequentemente disponibilidade de nitrogênio na forma absorvida pelas plantas (GÓES, 2007).

Segundo Prado (2009) o nitrogênio é um dos principais nutrientes responsáveis pelo desenvolvimento das plantas, pois influencia diretamente a expansão celular e a taxa fotossintética, sendo o mais exigido pelas 
hortaliças. Não foi possível ajustar nenhuma equação de regressão para a altura em função dos tempos de incorporação da jitirana. A altura média dessas plantas de cenoura observada foi de $28,7 \mathrm{~cm}$ em função dos tempos de incorporação da jitirana (FIG. 1B).

Bruno et al. (2007) cultivando cenoura com adubação orgânica e mineral, utilizaram como tratamentos orgânicos, adubação verde (crotalaria juncea L., incorporada 25 dias antes da semeadura) e composto orgânico, associados a aplicação de biofertilizantes. Esses autores encontraram plantas mais altas nos tratamentos que continham adubação verde, com altura média aproximadamente de $28 \mathrm{~cm}$, valor este próximo aos obtidos neste trabalho nas plantas adubadas com jitirana.

Não foi possível ajustar nenhuma equação de regressão para o número de folhas por planta, tanto em função das quantidades de jitirana incorporadas ao solo, como de seus tempos de incorporação. Observou-se que não houve variação no número de folhas por planta em função das quantidades de jitirana (FIG. 2A e 2B). Um valor médio de 6,8 folhas por planta foi registrado em função das quantidades de jitirana e de seus tempos de incorporação, respectivamente.

$\mathrm{O}$ número de folhas obtido nesta pesquisa foi semelhante aos obtidos por Teófilo et al. (2009), onde avaliaram o crescimento de três cultivares de cenoura (Alvorada, Brasília e Esplanada) e encontraram uma média de sete folhas por planta aos 84 dias após a semeadura, não sendo observada diferença significativa entre estas cultivares.

Para massa seca da parte aérea foi ajustada uma equação linear ascendente em função das quantidades crescentes de jitirana incorporadas ao solo, sendo observado que, para cada incremento de uma tonelada de jitirana incorporada ao solo se registrou um aumento na massa seca da parte aérea da cenoura de aproximadamente $0,03 \mathrm{t} \mathrm{ha}^{-1}$. Maior valor da massa seca da parte aérea de
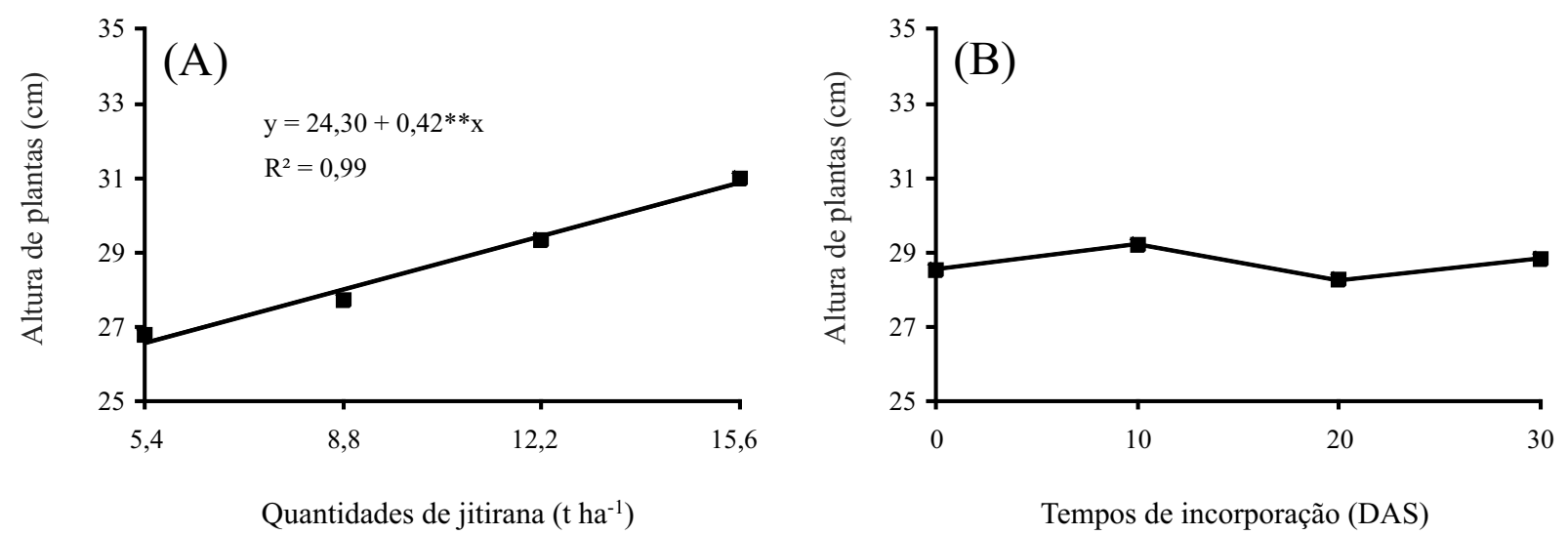

Figura 1 - Altura de plantas de cenoura em função de quantidades de jitirana incorporadas ao solo (A) e de seus tempos de incorporação antes da semeadura da cenoura (B)

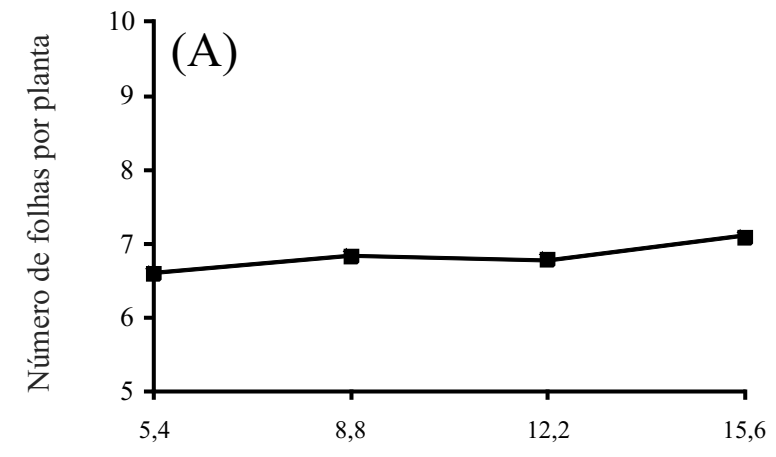

Quantidades de jitirana $\left(\mathrm{t} \mathrm{ha}^{-1}\right)$

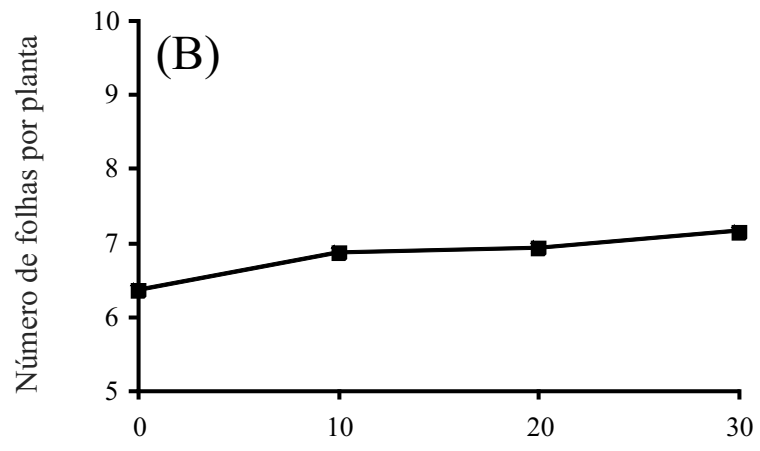

Tempos de incorporação (DAS)

Figura 2 - Número de folhas por plantas de cenoura em função de quantidades de jitirana incorporadas ao solo (A) e de seus tempos de incorporação antes da semeadura da cenoura (B) 
cenoura $\left(1,54 \mathrm{t} \mathrm{ha}^{-1}\right)$ foi obtido na quantidade de jitirana incorporada ao solo de $15,6 \mathrm{t} \mathrm{ha}^{-1}$, correspondendo a um incremento de $25,5 \%$, em comparação à quantidade de massa seca da parte aérea obtida na menor quantidade de jitirana (FIG. 3A). Não foi possível ajustar nenhuma equação de regressão da massa seca da parte aérea em função dos tempos de incorporação da jitirana. A massa seca média foi de $1,39 \mathrm{t} \mathrm{ha}^{-1}$ em função do tempo de incorporação da jitirana (FIG. 3B).

Linhares et al. (2009), estudando épocas de incorporação de jitirana na produção de rabanete, encontraram maior desenvolvimento da parte aérea nas plantas cultivadas aos 21 dias após a incorporação. Esse resultado diverge, em parte, dos obtidos nesse trabalho, podendo essa diferença ser atribuída ao menor ciclo da cultura do rabanete (em torno de 30 dias). Considerando que a mineralização e posterior liberação de nutrientes ocorre em torno de 40 dias, após a incorporação, pode ter ocorrido uma sincronia entre a disponibilidade de nutrientes oriundos da decomposição da jitirana e a fase de maior exigência nutricional do rabanete (TORRES et al., 2005).

Foi ajustada uma equação linear ascendente para a produtividade comercial da cenoura em função das quantidades crescentes de jitirana incorporadas ao solo. Para cada incremento de uma tonelada de jitirana incorporada ao solo se observou um aumento na produtividade comercial da cenoura de aproximadamente $0,36 \mathrm{t} \mathrm{ha}^{-1}$ (FIG. 4A). $\mathrm{O}$ maior valor de produtividade comercial da cenoura $\left(14,94 \mathrm{t} \mathrm{ha}^{-1}\right)$ foi obtido na quantidade de jitirana incorporada ao solo de 15,6 $\mathrm{t} \mathrm{ha}^{-1}$, correspondendo a um incremento de $32,6 \%$ em relação ao valor obtido na menor quantidade de jitirana $\left(5,4 \mathrm{t} \mathrm{ha}^{-1}\right)$ (FIG. 4A).
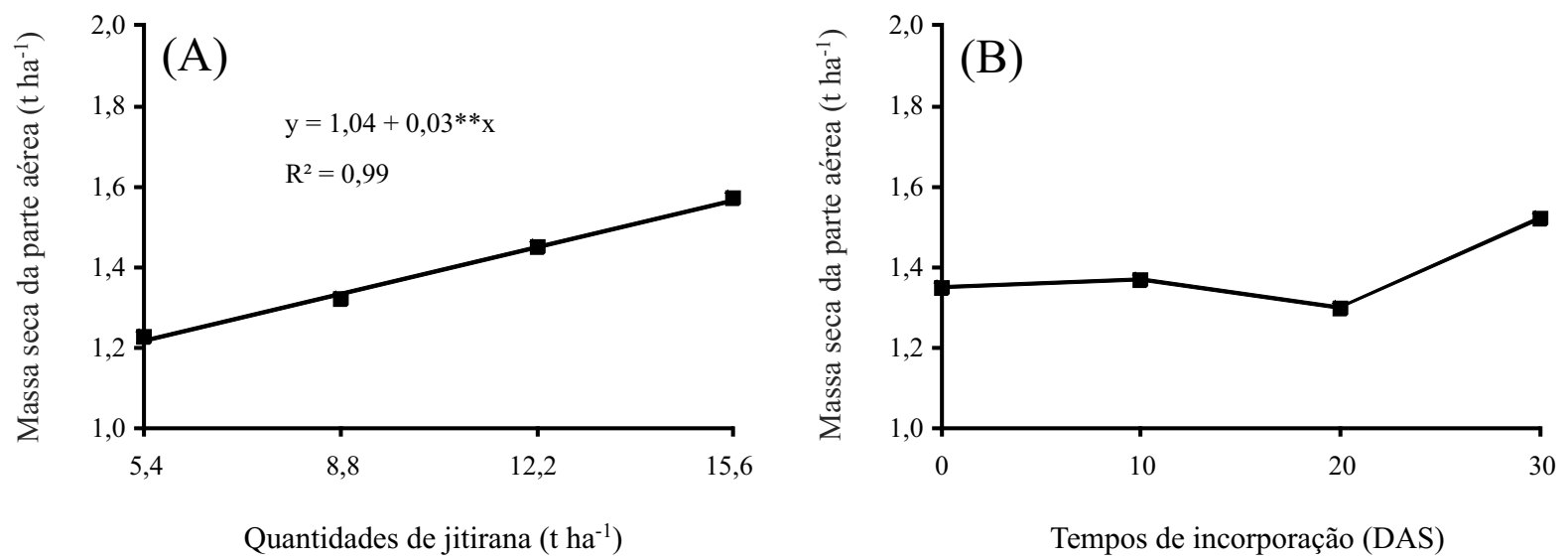

Figura 3 - Massa seca da parte aérea de plantas de cenoura em função de quantidades de jitirana incorporadas ao solo (A) e de seus tempos de incorporação antes da semeadura da cenoura (B)
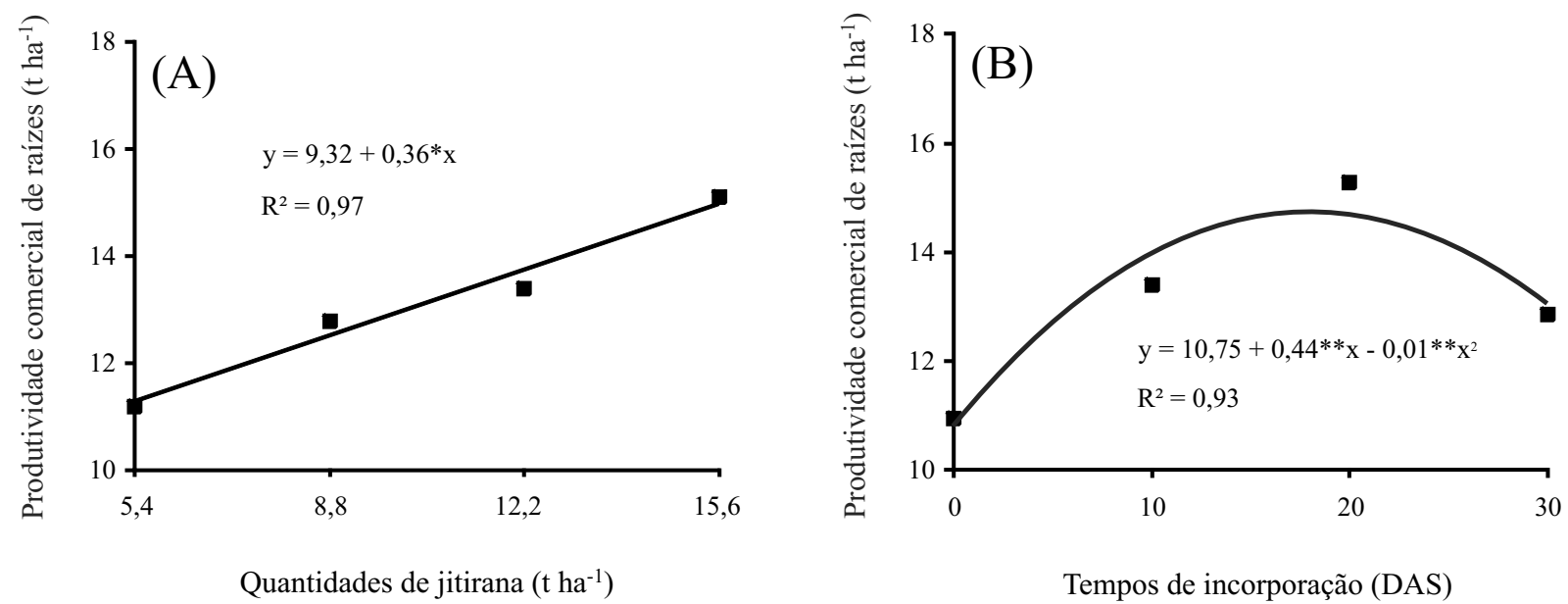

Figura 4 - Produtividade comercial de raízes de plantas de cenoura em função de quantidades de jitirana incorporadas ao solo (A) e de seus tempos de incorporação antes da semeadura da cenoura (B) 
Foi ajustada uma equação quadrática para a produtividade comercial em função dos tempos de incorporação da jitirana ao solo (FIG. 4B). A produtividade comercial de raízes aumentou até os 22 dias antes da semeadura da cenoura, atingindo o valor máximo de 15,59 $\mathrm{t} \mathrm{ha}^{-1}$, decrescendo a partir deste valor.

A produtividade comercial encontrada neste estudo foi maior que a obtida por Carvalho et al. (2005), que avaliaram a produtividade de raízes com a cultivar Brasília, e obtiveram produtividade comercial de $13,84 \mathrm{t} \mathrm{ha}^{-1}$. A resposta crescente na produtividade comercial em função do aumento nas quantidades de jitirana pode ser atribuída aos efeitos benéficos da adubação verde, onde se pode destacar o aumento da disponibilidade de nutrientes para as culturas de interesse comercial, a proteção do solo contra erosão, o favorecimento de organismos benéficos para agricultura e o controle de plantas espontâneas (ESPINDOLA et al., 2004). A resposta positiva evidencia a potencialidade desta espécie espontânea para ser utilizada como adubo verde.

Para a produtividade de raízes refugo, não foi possível ajustar nenhuma equação de regressão tanto em função das quantidades de jitirana incorporadas ao solo como dos tempos de incorporação (FIG. 5A e $5 \mathrm{~B}$ ). Uma produtividade média de raízes refugo de 4,05 $\mathrm{t} \mathrm{ha}^{-1}$ foi observada em função das quantidades de jitirana incorporadas ao solo (FIG. 5A) estando esse valor próximo ao obtido com o uso do esterco bovino $\left(3,91 \mathrm{tha}^{-1}\right)$. Em relação aos tempos de incorporação da jitirana, este valor foi de $4,05 \mathrm{t} \mathrm{ha}^{-1}$.

Não foi possível ajustar nenhuma equação de regressão para porcentagem de raízes longas de cenoura em função das quantidades de jitirana incorporadas ao solo.
A porcentagem média desse tipo de raízes observada foi de cerca de $12,0 \%$ em função das quantidades de jitirana incorporadas ao solo (FIG. 6A). Foi ajustada uma equação linear ascendente para porcentagem de raízes longas de cenoura em função dos tempos de incorporação da jitirana ao solo. Para cada incremento de um dia na incorporação se observou um aumento na porcentagem de raízes longas de cenoura de aproximadamente $0,35 \%$.

A maior porcentagem de raízes longas de cenoura $(17,22 \%)$ foi obtida com 30 dias de incorporação da jitirana ao solo antes da semeadura, correspondendo a um incremento de $100 \%$ em relação à menor quantidade de jitirana incorporada ao solo (FIG. 6B).

Para porcentagem de raízes médias de cenoura não foi possível ajustar nenhuma equação de regressão tanto em função das quantidades de jitirana incorporadas ao solo como dos tempos de incorporação (FIG. 7A e 7B). Porém, pelos dados observados verificou-se um pequeno incremento $(2,5 \%)$ na porcentagem de raízes médias entre a menor e a maior quantidade de jitirana incorporada (FIG. 7A).

A percentagem média de raízes médias de cenoura foi de $49,3 \%$ entre esta maior e menor quantidade de jitirana incorporada, valor este, abaixo do obtido com o uso de esterco bovino $(61,5 \%)$.

Em relação aos tempos de incorporação, registrou-se pelos dados observados um pequeno incremento $(4,5 \%)$ na porcentagem de raízes médias entre o tempo zero e o tempo 10 dias da incorporação da jitirana, decrescendo em seguida até aos 30 dias (FIG. 7B). A porcentagem média de raízes médias de cenoura entre o tempo 0 e o de 30 dias foi de $49,3 \%$.
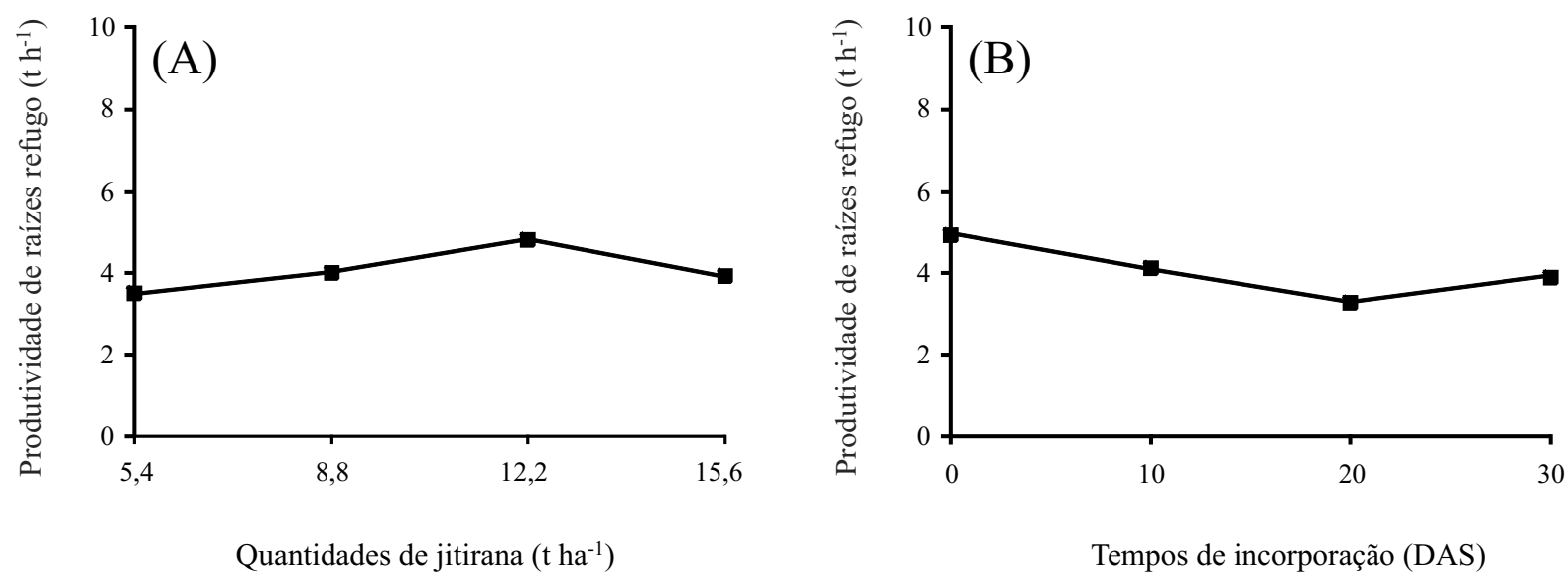

Figura 5 - Produtividade de raízes refugo em função de quantidades de jitirana incorporadas ao solo (A) e de seus tempos de incorporação antes da semeadura da cenoura (B) 

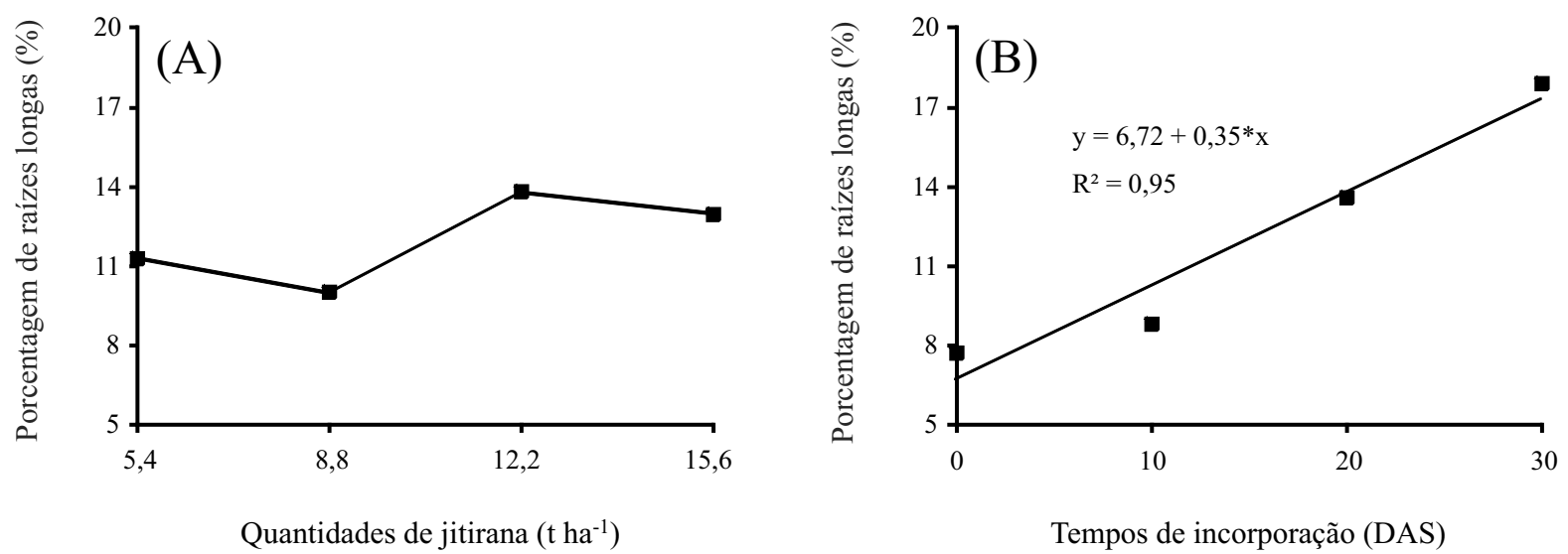

Figura 6 - Porcentagem de raízes longas em função de quantidades de jitirana incorporadas ao solo (A) e de seus tempos de incorporação antes da semeadura da cenoura (B)

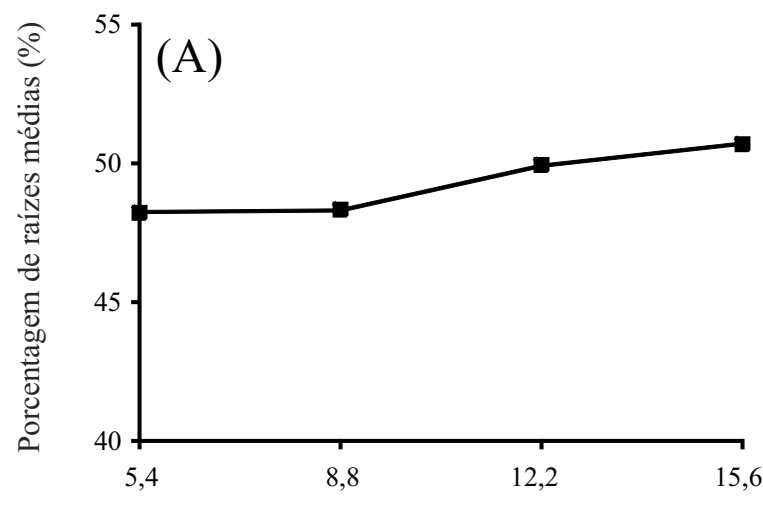

Quantidades de jitirana $\left(\mathrm{t} \mathrm{ha}^{-1}\right)$

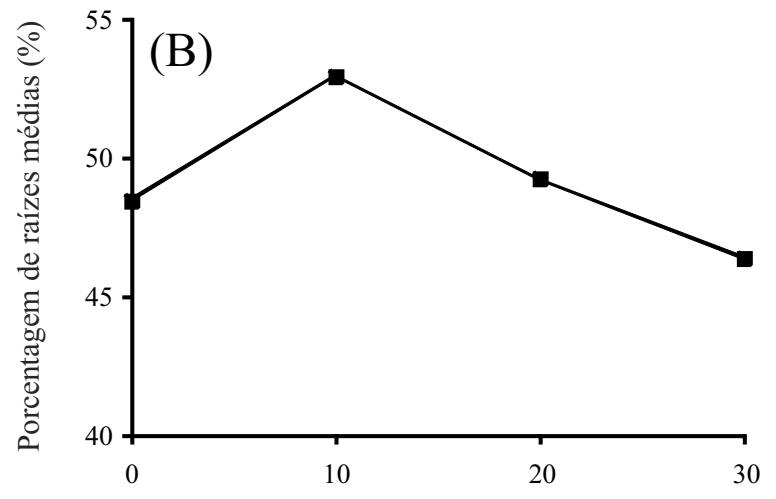

Tempos de incorporação (DAS)

Figura 7 - Porcentagem de raízes médias em função de quantidades de jitirana incorporadas ao solo (A) e de seus tempos de incorporação antes da semeadura da cenoura (B)

Para a porcentagem de raízes curtas de cenoura, não foi possível ajustar nenhuma equação de regressão tanto em função das quantidades de jitirana incorporadas ao solo como dos tempos de incorporação (FIG. 8A e $8 \mathrm{~B})$. Uma porcentagem média de raízes curtas de $39,1 \%$ foi observada em função das quantidades de jitirana incorporadas ao solo (FIG. 8A), sendo esse valor superior ao obtido com o uso do esterco bovino $(16,2 \%)$.

Em relação aos tempos de incorporação da jitirana, observou-se um pequeno decréscimo $(8,1 \%)$ na porcentagem de raízes curtas entre o tempo 0 e o tempo de 30 dias (FIG. 8B). A porcentagem média de raízes curtas entre esses tempos foi de $39,1 \%$.
Para altura de plantas, massa seca da parte aérea, produtividade comercial e percentagem de raízes longas foram observadas diferenças significativas entre os valores médios da testemunha e dos tratamentos provenientes do fatorial, com os maiores valores registrados na testemunha (cerca de $31,3 \%, 46,9 \%, 87,2 \%$ e $87,7 \%$ superior, respectivamente) enquanto que, para porcentagem de raízes curtas este maior valor foi observado em favor da média proveniente dos tratamentos fatorial.

Não se observou qualquer diferença significativa entre os valores médios da testemunha e dos provenientes dos tratamentos do fatorial no número de folhas por planta, produtividade refugo e na porcentagem de raízes médias de cenoura (TAB. 1). 

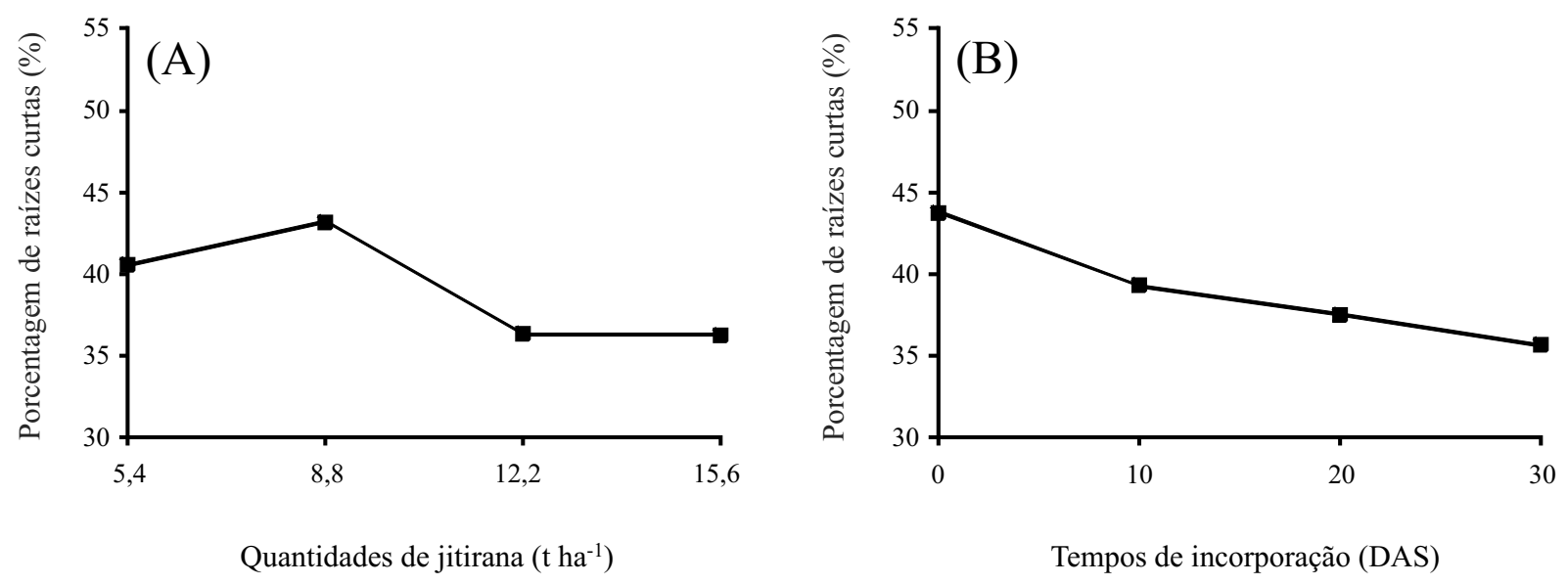

Figura 8 - Porcentagem de raízes curtas em função de quantidades de jitirana incorporadas ao solo (A) e de seus tempos de incorporação antes da semeadura da cenoura (B)

Tabela 1 - Valores médios da testemunha e das médias dos tratamentos provenientes do fatorial na altura de plantas (AP), número de folhas por planta (NF), massa seca da parte aérea (MSPA), produtividade comercial de raízes (PC), produtividade de raízes refugo (PR), porcentagem de raízes longas, de raízes médias e de raízes curtas em função de diferentes quantidades de jitirana incorporadas ao solo e de seus tempos de incorporação antes da semeadura da cenoura

\begin{tabular}{ccccccccc}
\hline Tratamentos & AP $(\mathrm{cm})$ & NF & $\begin{array}{c}\text { MSPA } \\
\left(\mathrm{t} \mathrm{ha}^{-1}\right)\end{array}$ & PC $\left(\mathrm{t} \mathrm{ha}^{-1}\right)$ & PR $\left(\mathrm{t} \mathrm{ha}^{-1}\right)$ & $\begin{array}{c}\text { Raízes } \\
\text { longas }(\%)\end{array}$ & $\begin{array}{c}\text { Raízes } \\
\text { medias }(\%)\end{array}$ & $\begin{array}{c}\text { Raízes } \\
\text { Curtas }(\%)\end{array}$ \\
\hline Testemunha $^{1}$ & $37,7 \mathrm{a}$ & $7,7 \mathrm{a}^{*}$ & $2,0 \mathrm{a}$ & $24,6 \mathrm{a}$ & $3,9 \mathrm{a}$ & $22,5 \mathrm{a}$ & $61,5 \mathrm{a}$ & $16,2 \mathrm{~b}$ \\
Fatorial $^{2}$ & $28,7 \mathrm{~b}$ & $6,8 \mathrm{a}$ & $1,4 \mathrm{~b}$ & $13,1 \mathrm{~b}$ & $4,1 \mathrm{a}$ & $12,0 \mathrm{~b}$ & $49,3 \mathrm{a}$ & $39,1 \mathrm{a}$ \\
\hline
\end{tabular}

*Médias da testemunha significativamente diferente da média dos tratamentos provenientes do fatorial pelo teste $\mathrm{t}$ de Student, ao nível de $5 \%$ de probabilidade; ${ }^{1}$ Testemunha esterco bovino

Para a produção classificada de raízes foi observada uma predominância da porcentagem de raízes médias $(49,3 \%)$ para os tratamentos provenientes do fatorial, bem como para a testemunha $(61,5 \%)$. Resultados semelhantes foram encontrados por diferentes autores (LOPES et al., 2008; OLIVEIRA et al., 2004). A predominância da porcentagem de raízes longas $(22,5 \%)$ foi observada para a testemunha e a porcentagem de raízes curtas $(39,1 \%)$ para os tratamentos provenientes do fatorial (TAB. 1).

\section{Conclusões}

1. Não houve interação significativa entre os fatores quantidades de jitirana incorporadas ao solo e seus tempos de incorporação em nenhuma característica avaliada da cenoura;

2. O melhor desempenho produtivo da cenoura foi obtido na quantidade de $15,6 \mathrm{t} \mathrm{ha}^{-1}$ de jitirana incorporada ao solo e no tempo de 20 dias antes de sua semeadura.

\section{Referências}

BRUNO, R. L. A. et al. Produção e qualidade de sementes e raízes de cenoura cultivada em solo com adubação orgânica e mineral. Horticultura Brasileira, v. 25, n. 02, p. 170-174, 2007.

CARMO FILHO, F. et al. Dados climatológicos de Mossoró: um município semi-árido nordestino. Mossoró: ESAM, 1991, 121p. (Coleção Mossoroense, série C, 30).

CARVALHO, A. M. et al. Produtividade, florescimento prematuro e queima-das-folhas em cenoura cultivada em sistema orgânico e convencional. Horticultura Brasileira, v. 23, n. 02, p. 250-254, 2005.

EMPRESA BRASILEIRA DE PESQUISA AGROPECUÁRIA - EMBRAPA. Centro Nacional de Pesquisa de solos. Sistema brasileiro de classificação de solos. 2. ed. Rio de Janeiro: Embrapa, 2006. 306p.

ESPINDOLA, J. A. A. et al. Estratégias para utilização de leguminosas para adubação verde em unidades de produção agroecológica. Seropédica: Embrapa Agrobiologia, 2004. 24 p. (Embrapa Agrobiologia, Documentos, 174). 
GIACOMINI, S. J. et al. Matéria seca, relação C/N e acúmulo de nitrogênio, fósforo e potássio em misturas de plantas de cobertura de solo. Revista Brasileira de Ciência do Solo, v. 27, n. 02, p. 325-334, 2003.

GÓES, S. B. Desempenho agroeconômico de alface lisa em função de quantidades de jitirana incorporadas ao solo e de seus tempos de decomposição. 2007. 84 f. Dissertação (Mestrado em Fitotecnia) - Universidade Federal Rural do SemiÁrido (UFERSA), Mossoró.

EMPRESA PERNAMBUCANA DE PESQUISA AGROPECUÁRIA - IPA. Recomendações de adubação para o estado de Pernambuco: $2^{\mathrm{a}}$ aproximação. 2. ed. Recife: IPA, 1998. 198 p.

JANDEL SCIENTIFIC. Table curve: curve fitting software. Corte Madera, CA: Jandel Scientific, 1991. 280 p.

KRONKA, S. N.; BANZATO, D. A. ESTAT: sistema para análise estatística versão 2. 3. ed. Jaboticabal: Funep, 1995. 243 p.

LANA, M. M.; VIEIRA, J. V. Fisiologia e manuseio póscolheita de cenoura. Brasília, EMBRAPA - Hortaliças. 2000. 15 p.

LIMA, G. K. L. et al. Uso de jitirana incorporada à adubação com esterco bovino na cultura da rúcula cv. Folha Larga. Revista Caatinga, v. 21, n. 04, p. 135-139, 2008.

LINHARES, P. C. F. et al. Adubação verde com jitirana na produção de rúcula. Revista Caatinga, v. 22, n. 03, p. 215219, 2009a.

LINHARES, P. C. F. et al. Avaliação da decomposição da jitirana em cobertura no desempenho agroeconômico de rúcula. Revista Caatinga, v. 22, n. 03, p. 71-76, 2009 b.

LINHARES, P. C. F. et al. Influência da jitirana em cobertura como adubação verde sobre o desempenho agronômico da alface. Revista Caatinga, v. 22, n. 04, p. 65-69, 2009c.
LINHARES, P. C. F. et al. Produção da rúcula em função de diferentes tempos de decomposição da malva veludo. Revista Caatinga, v. 22, n. 02, p. 50-54, 2009d.

LINHARES, P. C. F. et al. Produção de rúcula em função de diferentes tempos de decomposição de salsa. . Revista Caatinga, v. 22 , n. 02 , p. $200-205,2009$ e.

LINHARES, P. C. F. et al. Velocidade e tempo de decomposição da jitirana incorporada na cultura do rabanete. Revista Caatinga, v. 22, n. 02, p. 213-217, 2009 f.

LOPES, W. A. R. et al. Produtividade de cultivares de cenoura sob diferentes densidades de plantio. Revista Ceres, v. 55, n. 05, p. 482-487, 2008.

OLIVEIRA, C. A. et al. Decomposition of Archis pintoi and Hyparrhenia rufa litters in monoculture and intercropped systems under lowland soil. Pesquisa Agropecuária Brasileira, v, 38, n. 09, p. 1089-1195, 2003.

OLIVEIRA, E. Q. et al. Desempenho agroeconômico do bicultivo de alface em sistema solteiro e consorciado com cenoura. Horticultura Brasileira, v. 23, n. 02, p. 250-254, 2004.

PIMENTEL, M. S.; LANA, A. M. Q.; DE-POLLI, H. Rendimentos agronômicos em consórcio de alface e cenoura adubada com doses crescentes de composto orgânico. Revista Ciência Agronômica, v. 40, n. 01, p. 106-112, 2009.

PRADO, R. M. 500 Perguntas e respostas sobre nutrição de plantas. Jaboticabal: FCAV/GENPLANT, 2009. 108 p.

TEÓFILO, T. M. S. et al. Crescimento de cultivares de cenoura nas condições de Mossoró-RN. Revista Caatinga, v. 22, n. 01, p. 168-174, 2009.

TORRES, J. L. R. et al. Decomposição e liberação de nitrogênio de resíduos culturais de plantas de cobertura em um solo de cerrado. Revista Brasileira de Ciência do Solo, v. 29, n. 03, p. 609-618, 2005. 